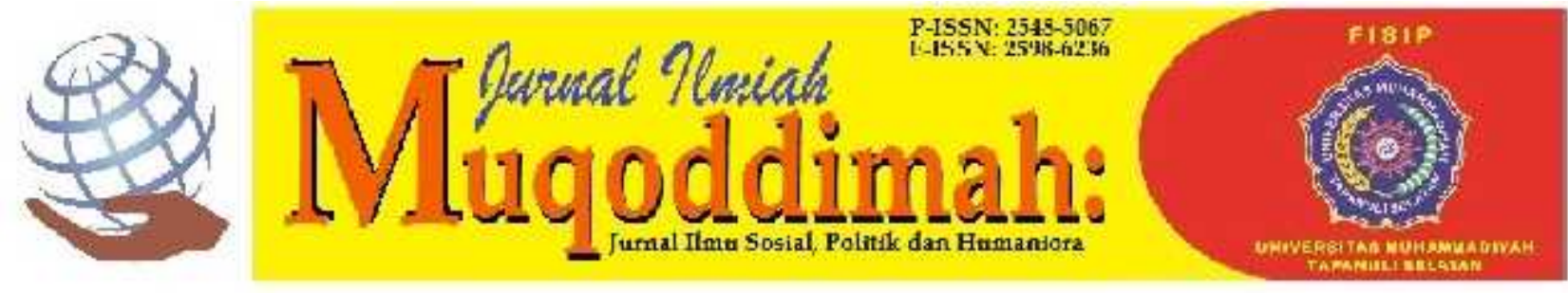

\title{
Pengaruh Kualitas Pelayanan Akademik dan Kompetensi Dosen Terhadap Kepuasan Mahasiswa
}

\author{
Syarif Firdaus ${ }^{1)}$, Darmo H. Suwiryo ${ }^{2)}$, Fenty Sukmawaty ${ }^{3}$ \\ Fakultas IImu Administrasi dan Humaniora, Universitas Muhammadiyah Sukabumi \\ JI. R. Syamsudin, S.H. No. 50, Cikole, Kec. Cikole, Kota Sukabumi, Jawa Barat

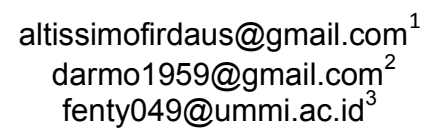

\begin{abstract}
Abstrak
Universitas Muhammadiyah Sukabumi (UMMI) merupakan Perguruan tinggi yang terbilang masih muda dengan jumlah mahasiswa yang cukup banyak. UMMI senantiasa berupaya untuk terus meningkatkan kualitas penyelenggaraannya melalui implementasi program-program prioritas berdasarkan hasil evaluasi diri khususnya dalam hal peningkatan kompetensi dosen dan kualitas pelayanannya. Namun masih terdapat permasalahan pada kepuasan mahasiswa yakni pada dimensi kesesuaian harapan yaitu mahasiswa belum merasa puas dengan layanan akademik Universitas Muhammadiyah Sukabumi. Tujuan penelitian ini adalah untuk mengukur pengaruh kualitas pelayanan akademik dan kompetensi dosen bidang akademik terhadap kepuasan mahasiswa. Metode yang digunakan dalam penelitian ini adalah metode deskriptif dan metode asosiatif dengan pendekatan kuantitatif. Teknik pengambilan data yang penelti gunakan dalam penelitian ini yaitu observasi, wawancara, kuesioner, studi kepustakaan dan dokumentasi. Penarikan sampel dalam penelitian ini menggunakan teknik sampling probability sampling dengan jenis proportionate stratified random sampling. Jumlah sampel yang diambil harus sama porsinya dengan jumlah mahasiswa sesuai dengan fakultasnya masing-masing, dengan jumlah keseluruhan 100 mahasiswa. Teknik analisis data yang digunakan adalah teknik analisis regresi linear berganda, termasuk uji koefisien determinasi, koefisien kolerasi ganda, uji secara simultan (uji F) dan uji secara parsial (uji T). Hasil penelitian menunjukan variabel kepuasan mahasiswa dengan persentase $84 \%$ dapat dijelaskan oleh kedua variabel independen yaitu kualitas pelayanan dan kompetensi dosen. Sementara $16 \%$ berasal dari faktor yang tidak diteliti dalam penelitian.
\end{abstract}

Kata kunci: Kepuasan Mahasiswa;Kompetensi Dosen; Kualitas Pelayanan.

\begin{abstract}
Muhammadiyah Sukabumi University (UMMI) is a relatively young university with a large number of students. UMMI always strives to continue to improve the quality of its implementation through the implementation of priority programs based on the results of self-evaluation, especially in terms of increasing the competence of lecturers and the quality of their services. However, there are still problems with student satisfaction, namely in the dimension of conformity with expectations, namely that students are not satisfied with the academic services of the Muhammadiyah Sukabumi University. The purpose of this study was to measure the effect of academic service quality and academic lecturer competence on student satisfaction. The method used in this research is descriptive method and associative method with a quantitative approach. The data collection techniques that the researcher used in this study were observation, interviews, questionnaires, literature
\end{abstract}


study and documentation. Sampling in this study using probability sampling with the type of proportionate stratified random sampling. The number of samples taken must be the same as the number of students according to each faculty, with a total of 100 students. The data analysis technique used is multiple linear regression analysis, including the coefficient of determination, multiple correlation coefficients, simultaneous test ( $F$ test) and partial test ( $T$ test). The results showed that the student satisfaction variable with a percentage of $84 \%$ could be explained by the two independent variables, namely service quality and lecturer competence. Meanwhile $16 \%$ came from factors not examined in the study

Keywords: Student Satisfaction; Lecturer Competency; Quality of Service.

\section{PENDAHULUAN}

Pendidikan Tinggi Swasta (PTS) merupakan satuan pendidikan yang diselenggarakan oleh organisasi masyarakat atau yayasan yang berbadan hukum. Pendidikan Tinggi Swasta berbentuk independen artinya dalam penyelenggaraannya Pendidikan Tinggi tersebut tidaklah dikelola oleh pemerintah daerah, ataupun nasional seperti Pendidikan Tinggi Negeri (PTN). Pendirian PTS dididirikan atas nama perorangan, kelompok atau yayasan yang dilatarbelakangi tujuan yang beragam baik keagamaan, kebudayaan ataupun kedaerahan. Pengelolaan PTS diarahkan untuk menjawab tantangan dan kebutuhan pasar, artinya kebutuhan pengguna jasa atau masyarakat terhadap pendidikan yang dihasilkan oleh PTS menjadi prioritas. Oleh karenanya setiap Perguruan Tinggi haruslah memiliki sumber daya manusia yang memiliki kualitas pelayanan dan kompetensi sumber daya manusia yang baik sehingga mampu memberikan kepuasan terhadap calon mahasiswa, mahasiswa ataupun pengguna lainnya yang berhubungan dengan Pendidikan Tinggi, sehingga semua tujuan dari didirikannya Pendidikan Tinggi tersebut dapat tercapai.

Universitas Muhammadiyah Sukabumi (UMMI) merupakan Perguruan tinggi yang baru menginjak usia 17 tahun dan dikatakan Perguruan Tinggi yang cukup muda. UMMI memiliki jumlah mahasiswa aktif sebanyak 4.157 orang dan pegawai sebanyak 254 orang yang terdiri dari Dosen sebanyak 164 orang dan Tenaga Kependidikan sebanyak 90 orang. Dengan usia yang terbilang masih muda serta jumlah mahasiswa yang cukup banyak tersebut UMMI senantiasa berupaya untuk terus meningkatkan kualitas penyelenggaraannya melalui implementasi program-program prioritas berdasarkan hasil evaluasi diri khususnya dalam hal peningkatan kompetensi dosen dan kualitas pelayanannya.

Kualitas pendidikan dan layanan pendidikan yang baik, maka tercapailah kepuasan mahasiswa. Pada kenyataanya, perguruan tinggi khususnya UMMI masih memiliki beberapa permasalahan yang menimbulkan ketidakpuasan bagi mahasiswa. Meskipun sejauh ini UMMI selalu berusaha untuk meningkatkan kualitas pelayanannya dengan berbagai pelatihan kompetensi SDMnya. Masalah-masalah yang ada di UMMI tersebut bertumpu pada aspek pelayanan akademik serta sarana dan prasarana yang dinilai masih belum sepenuhnya memadai.

Hasil dari observasi dan wawancara langsung dengan tujuh mahasiswa di UMMI, yakni masalah pelayanan akademik yang sering dihadapi oleh mahasiswa meliputi jadwal perwalian yang kurang jelas, jadwal kuliah yang tidak konsisten, kesibukan dosen pengajar, keterlambatan pengumuman nilai ujian, tidak transparannya nilai perkuliahan, sulitnya menguhubungi dosen tertentu dalam melakukan bimbingan penyusunan penelitian. Selain itu, mahasiswa juga menilai tentang proses pembelajaran dan pelayanan institusi yang ada, setidaknya ada beberapa hal yang menjadi sorotan dalam pelaksanaan pembelajaran dan pelayanan terhadap mahasiswa, antara lain pembelajaran yang masih cenderung monoton, mahasiswa yang dirasa kurang aktif dalam kegiatan belajar mengajar dan kurang adanya trobosan baru dalam sistem pembelajaran. Dari sekian permasalahan yang timbul, setidaknya akan mempengaruhi kepuasan mahasiswa. Mahasiswa yang selama ini telah banyak 
merasakan pembelajaran dan mendapatkan pelayanan, masih samar akan kepuasan yang didapat mahasiswa.

Data E-Complaint yang ada di Lembaga Penjamin Mutu Universitas Muhammadiyah Sukabumi jika kita perhatikan masih saja ada konsumen dalam hal ini mahasiswa yang belum merasa puas terhadap pelayanan yang telah diberikan oleh Universitas Muhammadiyah Sukabumi. Berikut grafik persentase keluhan yang masuk ke Lembaga Penjamin Mutu Universitas Muhammadiyah Sukabumi :

Gambar 1 Statistik Keluhan Mahasiswa Universitas Muhammadiyah Sukabumi

\section{Statistik Keluhan}

\section{Grafik Statistik Keluhan Berdasarkan Lingkup Kcluhan}

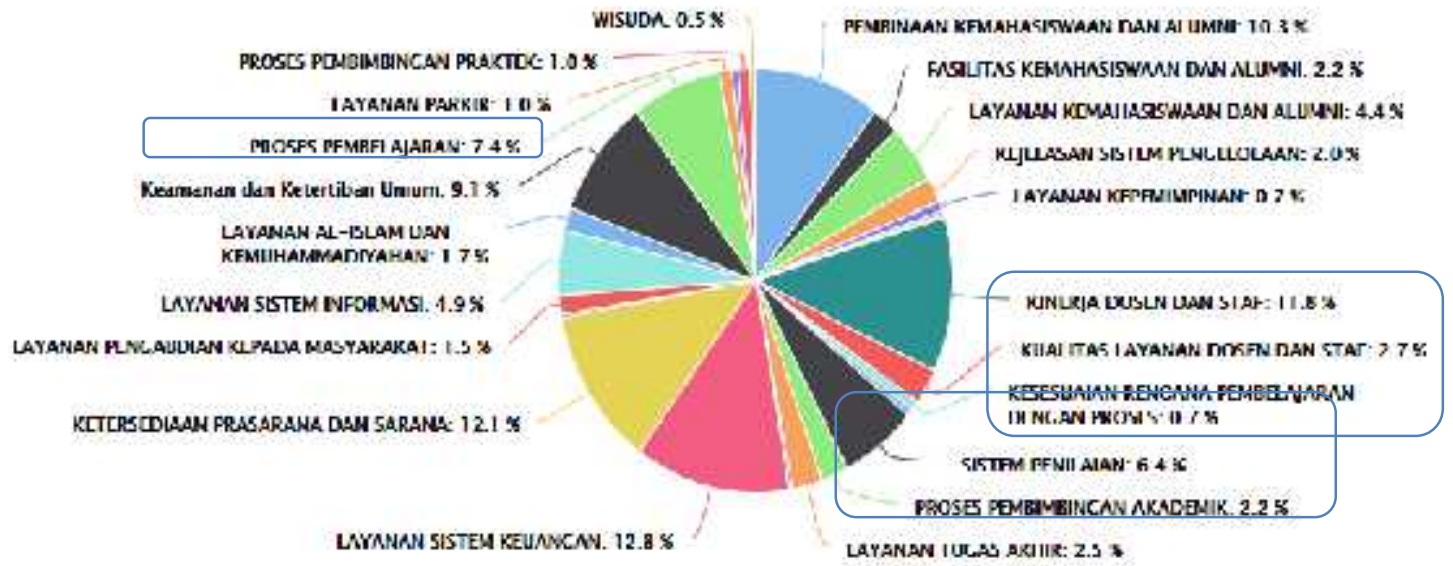

Sumber : (Universitas Muhammadiyah Sukabumi, 2020)

Dari gambar 1 terlihat bahwa lingkup keluhan tertinggi yang ada pada bidang akademik yaitu kinerja dosen. UMMI dengan visinya sebagai lembaga pendidikan tinggi yang unggul dalam keilmuan dan keislaman, menawarkan tantangan yang cukup berat. sebab untuk mencapai unggul tersebut UMMI masih harus berjuang memperkuat pranata kelembagaannya. Mahasiswa tidak hanya diberikan ilmu saja, tetapi bagaimana tingkat kepuasannya selama menimba ilmu di UMMI.

Dengan demikian, pengukuran kepuasan mahasiswa, sebagai pengguna jasa pada suatu perguruan tinggi khususnya UMMI, sangatlah penting dan perlu dilakukan, karena berkaitan erat dengan kinerja perguruan tinggi. Lebih dari itu, tingkat kepuasan pelanggan atas kualitas layanan yang telah diberikan UMMI dalam hal layanan akademik juga dapat dikaitkan dengan perkembangan jumlah calon mahasiswa yang masuk setiap tahunnya, dengan asumsi bahwa mahasiswa yang sangat puas secara tidak langsung akan menjadi agen promosi bagi perguruan tinggi yang bersangkutan untuk menarik calon mahasiswa baru.

Kualitas pelayanan akan memberikan dampak terhadap instansi pendidikan, apabila pelayanan dalam instansi tersebut buruk atau kurang baik maka para mahasiswa akan berpindah ke perguruan tinggi lainnya dan mahasiswa tersebut akan memberitahu temantemannya, saudaranya, tetangganya ataupun orang-orang yang berada disekitar tempat tinggalnya, dan ini akan menyebabkan mahasiswa yang masuk akan menurun dan mahasiswa merasa pelayanan yang diberikan oleh petugas buruk.

Kepuasan mahasiswa juga sangat ditentukan oleh kompetensi sumber daya manusia. Hal tersebut berakaitan dengan kinerja sumber daya manusia (SDM), sarana prasarana dan 
atmosfer akademik. Tenaga pengajar tentu memiliki kedudukan yang sangat penting pada suatu perguruan tinggi salah satunya yaitu sebagai penyedia layanan pendidikan berupa ilmu yang diberikan. Kinerja suatu lembaga perguruan tinggi ditentukan oleh kompetensi-kompetensi dosen dalam menjalankan tugasnya memberikan sebuah pelayanan kepada mahasiswa. Maka dari itu, kualitas sebuah perguruan tinggi bergantung pada faktor-faktor tersebut yang terintegrasi satu sama lain.

Semua bentuk pelayanan dan upaya peningkatan kapasitas maupun kompetensi dosen di Universitas Muhammadiyah Sukabumi selalu ditingkatkan setiap tahunnya melalui pelatihanpelatihan dari hasil evaluasi-evaluasi yang dilakukan, karena UMMI percaya bahwa dengan peningkatan kapasitas dosen tentu akan menambah kompetensi yang dimiliki oleh dosen. Namun dari hasil observasi, wawancara, dokumentasi yang telah dipaparkan diatas, masih terdapat permasalahan pada kepuasan mahasiswa yakni pada dimensi kesesuaian harapan yaitu mahasiswa belum merasa puas dengan layanan akademik Universitas Muhammadiyah Sukabumi. Permasalahan tersebut diduga disebabkan oleh pelayanan akademik yang belum handal dalam memberikan pelayanan. Penyebab lainnya disebabkan oleh dosen belum terampil untuk melaksanakan tugas-tugas rutin sesuai dengan standar di tempat kerja.

Dalam penelitian ini penulis menjelaskan bahwa dari hasil pencarian data ke Lembaga Penjamin Mutu (LPM) didapatkan data bahwa persentase keluhan yang masuk untuk layanan bidang akademik sangat besar. Padahal UMMI Setiap tahunnya selalu memiliki program pengembangan para pegawai melalui pelatihan, studi banding, workshop dan hal yang sejenis lainnya. Zeithaml et al., (2018:79) menjelaskan bahwa kualitas pelayanan yaitu :

Service quality is a focused evaluation that reflects the customer's perception of reliability, assurance, responsiveness, empathy, and tangibles. Satisfaction, on the other hand, is more inclusive: it is influenced by perceptions of service quality, product quality, and price, as well as situational factors and personal factors.

Yang diartikan kualitas pelayanan adalah evaluasi terfokus yang mencerminkan persepsi pelanggan tentang keandalan, jaminan, daya tanggap, empati, dan berwujud. Kepuasan, di sisi lain, lebih inklusif: dipengaruhi oleh persepsi tentang kualitas layanan, kualitas produk, dan harga, serta faktor situasional dan personal faktor. Kualitas pelayanan menurut (Zeithaml et al., 2018:87), dapat diukur dari lima dimensi, yaitu 1) Tangibles (berwujud); 2) Realiability (kehandalan); 3) Responsiveness (ketanggapan); 4) Assurancess (jaminan); 5) Empathy (perhatian). Sedarmayanti (dalam Daly, 2019: 91) mengemukakan bahwa kompetensi adalah karakteristik mendasar yang dimiliki seseorang yang berpengaruh langsung terhadap, atau dapat memprediksikan kinerja yang sangat baik. Menurut Tjiptono (2014) jika suatu SDM tidak memiliki kompetensi dan pengetahuan yang tinggi, dapat menyebabkan buruknya kualitas pelayanan, dan sebaliknya, jika SDM / karyawan memiliki kompetensi dan pengetahuan tinggi, hal tersebut dapat meningkatkan kualitas pelayanan asalkan pekerjaan yang mereka lakukan sesuai dengan tugas yang diberikan. McClelland, Boyatzis, Spencer \& Spencer (dalam Melly, 2017 : 12) mengemukakan lima karakteristik kompetensi yaitu 1) Motives (Motivasi); 2) Traits (Karakter); 3) Self-concept (Konsep Diri); 4) Knowledge (Pengetahuan); dan 5) Skills (Keterampilan). Kotler dalam Arief (2007:167) mendefinisikan kepuasan pelanggan adalah perasaan seseorang setelah membandingkan antara kinerja yang ia rasakan/alami terhadap harapannya. Hawkins dan Lonney (dalam Tjiptono (2014:101) juga mengemukakan bahwa aspek pembentuk kepuasan terdiri kesesuaian dengan harapan, minat berkunjung kembali dan kesediaan merekomendasikan.

Menurut Lupioyadi (2006) yang menyatakan bahwa publik akan merasa puas bila mereka mendapatkan pelayanan yang baik atau yang sesuai dengan yang diharapkan. Hasil penelitian ini juga sesuai dengan penelitian yang dilakukan Yuniarty (2014), Putra, et., al (2015 ), Wulandari \& Suryani (2017) bahwa kualitas pelayanan berpengaruh signifikan terhadap kepuasan. 
Tjiptono (dalam Andhiny, 2017:27), menyatakan jika suatu sumber daya manusia tidak memiliki kompetensi dan pengetahuan yang tinggi, dapat menyebabkan buruknya kualitas pelayanan, dan sebaliknya, jika sumber daya manusia memiliki kompetensi dan pengetahuan tinggi, hal tersebut dapat meningkatkan kualitas pelayanan asalkan pekerjaan yang mereka lakukan sesuai dengan tugas yang diberikan. Hasil penelitian ini juga sesuai dengan penelitian yang dilakukan Santoso \& Ekawati (2018) bahwa kompetensi kerja berpengaruh signifikan terhadap kepuasan.

Berdasarkan permasalahan yang di uraikan di atas, Maka penulis tertarik untuk meneliti yang di tuangkan dalam sebuah penelitian dengan judul Pengaruh Kualitas Layanan Akademik dan Kompetensi Dosen Terhadap Kepuasan Mahasiswa Di Lingkungan Universitas Muhammadiyah Sukabumi.

\section{METODE}

Penelitian ini dilaksanakan pada Universitas Muhammadiyah Sukabumi. Metode yang digunakan dalam penelitian ini adalah metode deskriptif dan metode asosiatif dengan pendekatan kuantitatif. Teknik pengambilan data yang penelti gunakan dalam penelitian ini yaitu observasi, wawancara, kuesioner, studi kepustakaan dan dokumentasi. Penarikan sampel dalam penelitian ini menggunakan teknik sampling probability sampling dengan jenis proportionate stratified random sampling. Proportionate stratified random sampling adalah pengambilan sampel dari anggota populasi secara acak dan berstrata secara proporsional. Jumlah sampel yang diambil harus sama porsinya dengan jumlah mahasiswa sesuai dengan fakultasnya masing-masing, dengan jumlah keseluruhan 100 mahasiswa. Teknik analisis data yang digunakan adalah teknik analisis regresi linear berganda, termasuk uji koefisien determinasi, koefisien kolerasi ganda, uji secara simultan (uji F) dan uji secara parsial (uji T).

\section{HASIL DAN PEMBAHASAN}

\section{Hasil Analisis Regresi Linear Berganda}

Analisis regresi linear berganda digunakan oleh peneliti, untuk meneliti suatu pengaruh dari beberapa variabel yang berkolerasi dengan variabel yang lain yang akan diuji. Dari hasil regresi linear berganda ini dapat dilihat pada Tabel 1 :

Tabel 1

Hasil Uji Regresi Linear Berganda

\begin{tabular}{|c|c|c|c|c|c|c|}
\hline \multicolumn{7}{|c|}{ Coefficients $^{a}$} \\
\hline \multirow{2}{*}{\multicolumn{2}{|c|}{ Model }} & \multicolumn{2}{|c|}{$\begin{array}{l}\text { Unstandardized } \\
\text { Coefficients }\end{array}$} & \multirow{2}{*}{$\begin{array}{c}\text { Standardized } \\
\text { Coefficients } \\
\text { Beta }\end{array}$} & \multirow[b]{2}{*}{$t$} & \multirow[b]{2}{*}{ Sig. } \\
\hline & & $\mathrm{B}$ & Std. Error & & & \\
\hline \multirow[t]{3}{*}{1} & (Constant) & 2.020 & 1.712 & & 1.180 & .241 \\
\hline & $\begin{array}{l}\text { Kualitas } \\
\text { Pelayanan }\end{array}$ & .216 & .054 & .365 & 3.992 & .000 \\
\hline & $\begin{array}{l}\text { Kompetensi } \\
\text { Dosen }\end{array}$ & .339 & .054 & .573 & 6.270 & .000 \\
\hline
\end{tabular}

Sumber : Data Primer (Kuesioner), 2020

Dari hasil uji regresi linear berganda, maka dapat diperoleh persamaan:

$$
Y=2,020+0,216 X_{1}+0,339 X_{2}
$$


Koefisien Determinasi $\left(\mathbf{R}^{2}\right)$

Tabel 2

Hasil Koefisien Determinasi

\begin{tabular}{|c|c|c|c|c|}
\hline \multicolumn{5}{|c|}{ Model Summary ${ }^{b}$} \\
\hline Model & $\mathrm{R}$ & R Square & $\begin{array}{l}\text { Adjusted R } \\
\text { Square }\end{array}$ & $\begin{array}{l}\text { Std. Error of the } \\
\text { Estimate }\end{array}$ \\
\hline 1 & $.917^{\mathrm{a}}$ & .840 & .838 & 4.19276 \\
\hline
\end{tabular}

Sumber : Data Primer (Kuesioner), 2020

Hasil Tabel 2 menunjukan besarnya nilai adjusted $R^{2}$ yaitu 0,840 ; maka hal ini menunjukan $84 \%$ variabel kepuasan mahasiswa dapat dijelaskan oleh kedua variabel independen yaitu kualitas pelayanan dan kompetensi dosen. Sementara $16 \%$ berasal dari faktor yang tidak diteliti dalam penelitian.

\section{Koefisien Kolerasi Ganda}

Tabel 3

Hasil Koefisien Kolerasi Ganda

\begin{tabular}{|l|r|r|r|c|}
\hline \multicolumn{6}{|c|}{ Model Summary } \\
\hline Model & $\mathrm{R}$ & $\mathrm{R}$ Square & $\begin{array}{c}\text { Adjusted R } \\
\text { Square }\end{array}$ & $\begin{array}{c}\text { Std. Error of the } \\
\text { Estimate }\end{array}$ \\
\hline 1 & $.917^{\mathrm{a}}$ & .840 & .838 & 4.19276 \\
\hline
\end{tabular}

a. Predictors: (Constant), Kompetensi Dosen, Kualitas Pelayanan

b. Dependent Variable: Kepuasan Mahasiswa

Sumber : Data Primer (Kuesioner), 2020

Hasil Tabel 3 menunjukan bahwa hasil yang diperoleh angka $R$ sebesar 0,917 hasil ini berada pada kategori $0,80-1,000$. Hal ini menunjukan bahwa adanya hubungan yang sangat kuat antara kualitas pelayanan dan kompetensi dosen dengan kepuasan mahasiswa.

\section{Uji Signifikasi Secara Simultan (Uji F)}

Tabel 4

Hasil Uji F

\begin{tabular}{|l|l|r|r|r|r|c|}
\hline \multicolumn{7}{|l|}{ ANOVA $^{\mathrm{a}}$} \\
\hline \multirow{2}{|l|}{ Model } & Sum of Squares & \multicolumn{1}{c|}{ df } & Mean Square & F & \multicolumn{1}{c|}{ Sig. } \\
\hline \multirow{4}{*}{1} & Regression & 10002.814 & 2 & 5001.407 & 284.507 & $.000^{\mathrm{b}}$ \\
\cline { 2 - 7 } & Residual & 1898.555 & 108 & 17.579 & & \\
\cline { 2 - 7 } & Total & 11901.369 & 110 & & & \\
\hline \multicolumn{2}{|l}{ a. Dependent Variable: Kepuasan Mahasiswa } \\
\hline
\end{tabular}

Sumber : Data Primer (Kuesioner), 2020 
Hasil Tabel 4 menunjukan bahwa hasil uji $\mathrm{F}$ yang telah dilakukan dapat diperoleh nilai sig. $0,000<0,05$; nilai $F_{\text {hitung }} 284,507>F_{\text {Tabel }} 3,09$. Artinya bahwa kualitas pelayanan dan kompetensi dosen secara bersama-sama (simultan) berpengaruh terhadap kepuasan mahasiswa. Hal ini dapat disimpulkan bahwa mahasiswa akan merasa puas apabila kualitas pelayanan dan kompetensi dosen mendapatkan perhatian yang besar. (100-2-1)

Hasil penelitian ini sejalan dengan penelitian yang dilakukan oleh Marzuki et al., (2019), menyatakan bahwa, "Kualitas layanan dan kompetensi dosen berpengaruh signifikan terhadap kepuasan mahasiswa pada STIK (Sekolah Tinggi IImu Kesehatan) Avicenna Kendari, artinya semakin baik kualitas layanan dan kompetensi dosen maka kepuasan mahasiswa akan semakin meningkat."

\section{Uji Signifikasi Secara Parsial (Uji T)}

Tabel 5

Hasil Uji T

\begin{tabular}{|c|c|c|c|c|c|c|}
\hline \multicolumn{7}{|c|}{ Coefficients $^{a}$} \\
\hline \multirow{2}{*}{\multicolumn{2}{|c|}{ Model }} & \multicolumn{2}{|c|}{$\begin{array}{l}\text { Unstandardized } \\
\text { Coefficients }\end{array}$} & \multirow{2}{*}{$\begin{array}{c}\text { Standardized } \\
\text { Coefficients } \\
\text { Beta }\end{array}$} & \multirow[b]{2}{*}{$t$} & \multirow[b]{2}{*}{ Sig. } \\
\hline & & $\mathrm{B}$ & Std. Error & & & \\
\hline \multirow[t]{3}{*}{1} & (Constant) & 2.020 & 1.712 & & 1.180 & .241 \\
\hline & $\begin{array}{l}\text { Kualitas } \\
\text { Pelayanan }\end{array}$ & .216 & .054 & .365 & 3.992 & .000 \\
\hline & \begin{tabular}{|l} 
Kompetensi \\
Dosen
\end{tabular} & .339 & .054 & .573 & 6.270 & .000 \\
\hline
\end{tabular}

Hasil Tabel 5 menunjukan bahwa hasil uji T yang telah dilakukan pada variabel kualitas pelayanan menghasilkan nilai dengan sig. 0,000 <0,05; nilai $\mathrm{T}_{\text {hitung }} 3,992>\mathrm{T}_{\text {Tabel }} 1,98472$. Artinya bahwa kualitas pelayanan secara parsial berpengaruh positif dan signifikan terhadap kepuasan mahasiswa, Hal ini menunjukan bahwa mahasiswa memberikan tanggapan baik pada kualitas pelayanan sehingga mahasiswa merasa puas dengan kualitas pelayanan Universitas Muhammadiyah Sukabumi.

Hasil penelitian ini sejalan dengan penelitian yang dilakukan Marzuki et al., (2019), Susanto (2014), Saifuddin \& Sunarsih (2016), dan Taman et al., (2013) menyatakan bahwa, "kualitas pelayanan berpengaruh positif dan signifikan terhadap kepuasan mahasiswa."

Selanjutnya variabel kemampuan kerja menghasilkan nilai dengan sig. 0,000<0,05; nilai $T_{\text {hitung }} 6,270>T_{\text {Tabel }}$ 1,98472. Artinya bahwa kompetensi dosen secara parsial berpengaruh positif dan signifikan terhadap kepuasan mahasiswa.". Dari hasil yang diperoleh dapat disimpulkan bahwa kompetensi dosen berpengaruh signifikan terhadap kepuasan mahasiswa. Hal ini menunjukan bahwa mahasiswa memberikan tanggapan baik pada kompetensi dosen sehingga mahasiswa merasa puas dengan kualitas pelayanan Universitas Muhammadiyah Sukabumi.

Hasil penelitian ini sejalan dengan penelitian yang dilakukan oleh Marzuki et al., (2019), Isnaini et al., (2015), Teguh Santoso \& Ekawaty (2018), dan Taman et al., (2013) menyatakan bahwa, "kompetensi dosen berpengaruh positif dan signifikan terhadap kepuasan mahasiswa." 


\section{SIMPULAN DAN SARAN}

Berdasarkan dari hasil pengujian uji $\mathrm{T}$, kualitas pelayanan berpengaruh positif dan signifikan terhadap kepuasan mahasiswa dan kompetensi dosen secara parsial berpengaruh positif dan signifikan terhadap kepuasan mahasiswa. Dan secara simultan pada variabel kualitas pelayanan dan kompetensi dosen secara bersama-sama (simultan) berpengaruh positif dan signifikan terhadap kepuasan mahasiswa.

Berdasarkan hasil penelitian yang diperoleh dari analisis data, maka saran yang dapat diberikan oleh peneliti kepada Universitas Muhammadiyah Sukabumi adalah : (1) Disarankan kepada pihak universitas untuk dapat meningkatkan pelayanannya dalam hal konsistensi kinerja dosen. (2) Diharapkan peran dosen dapat lebih memotivasi mahasiswa untuk berprestasi dengan baik dalam bidang akademik maupun non akademik sebagai wujud kepeduliannya terhadap eksistensi mahasiswanya. (3) Penelitian ini diharapkan dapat dijadikan sebagai sarana informasi sehingga dalam penelitian selanjutnya dapat memperbaiki keterbatasan yang ada dalam penelitian ini dengan melakukan penelitian pada sektor lain dan memperluas variabel mengenai kualitas pelayanan, kompetensi dosen, dan kepuasan mahasiswa agar dapat mengembangkan penelitian dengan menggunakan variabel lain, sehingga dapat mendukung dalam penelitian selanjutnya.

\section{DAFTAR PUSTAKA}

Arief. (2007). Pemasaran Jasa \& Kualitas Pelayanan. Malang: Bayumedia Publishing.

Daly, Hamlan. (2015). Pengaruh Kompetensi, Disiplin dan Kompensasi Terhadap Kinerja Pegawai Badan Pemberdayaan Perempuan dan Keluarga Berencana Daerah Provinsi Sulawesi Tengah. e-Jurnal Katalogis, Volume 3 Nomor 1, Januari 2015 hlm 84-94 ISSN: 2302-2019. Sulawesi Tengah.

Isnaini, M., Kusuma, D., \& Noviani, L. (2015). Pengaruh Kompetensi Dosen Dan Fasilitas Belajar Terhadap Kepuasan Mahasiswa Pendidikan Ekonomi Fkip Uns. BISE: Jurnal Pendidikan Bisnis Dan Ekonomi, 1(2), 1-20. https://jurnal.uns.ac.id/bise/article/view/17968

Lupiyoadi dan Hamdani. (2006). Manajemen Pemasaran jasa Edisi kedua. Jakarta. Penerbit Salemba Empat.

Marzuki, M. F., Nurwati, \& Rommy, N. (2019). Pengaruh Kualitas Layanan Dan Kompetensi

Dosen Terhadap Kepuasan Mahasiswa. JUMBO ( Jurnal Manajemen , Bisnis , Dan Organisasi ) Univerisias Halu Oleo, 3(3), 85-97.

Melly dkk. (2017). Upaya Meningkatkan Aktivitas Belajar Siswa Dengan Menerapkan Model Pembelajaran Problem Posing Tipe Problem Pre Solution. Jurnal Penelitian Pembelajaran Matematika Sekolah, Vol 1. No 1 Hal 66-73.

Saifuddin, \& Sunarsih. (2016). Pengaruh Kualitas Pelayanan terhadap Kepuasan Mahasiswa UIN Sunan Kalijaga Yogyakarta 1. 8(2), 177-216.

Susanto, H. (2014). Pengaruh Layanan Akademik Terhadap Kepuasan Mahasiswa Program Pascasarjana Universitas Terbuka Pada Unit Program Belajar Jarak Jauh (Upbjj) Mataram. Jurnal Pendidikan Terbuka Dan Jarak Jauh, 15(2), 1-98.

Taman, A., Sukirno, S., Sari, A. R., Setiawan, N., \& Pustikaningsih, A. (2013). Analisis Kualitas Pelayanan Terhadap Kepuasan Mahasiswa Pada Fakultas Ekonomi Universitas Negeri Yogyakarta. Nominal, Barometer Riset Akuntansi Dan Manajemen, 2(1), 99-111. https://doi.org/10.21831/nominal.v2i1.1651

Teguh Santoso, M. P., \& Ekawaty, N. (2018). Pengaruh Kompetensi Dosen Terhadap Kinerja Akademik Dan Kepuasan Mahasiswa: Studi Kasus Kelas Internasional Di Program Studi Manajemen Dan Akuntansi Fakultas Ekonomi Dan Bisnis Universitas Singaperbangsa Karawang (2017-2018). Buana IImu, 3(1), 33-51. https://doi.org/10.36805/bi.v3i1.454

Tjiptono, Fandy. (2014). Pemasaran Jasa. Andi : Yogyakarta 
Yuniarti. (2016). Pengaruh Kualitas Produk, Harga dan Kepercayaan Terhadap Keputusan Pembelian Produk Fashion Secara Online. Jurnal Penelitian Universitas Jambi: Seri Humaniora, 18 (1). June 28, 2018.

Zeithaml, V. A., Bitner, M. J., \& Gremler, D. D. (2018). Services Marketing: Integrating Customer Focus Across the Firm Seventh Edition. In Business Horizons (Vol. 51, Issue 3). The McGraw-Hill Companies. https://doi.org/10.1016/j.bushor.2008.01.008 